\title{
ANALISIS TEKNIK PENERJEMAHAN ADAPTASI DAN VARIASI PADA SUBTITLE FILM BATMAN VERSI BAHASA JAWA MATARAMAN
}

\author{
Anita Rahma, Diah Kristina, Sri Marmanto \\ Universitas Sebelas Maret Surakarta \\ anitarahma@student.uns.ac.id
}

\begin{abstract}
The aim of this study is to identify and describe the cultural elements translated using adaptation technique and linguistic elements translated using variation technique in Batman movie subtitled into Mataraman Javanese. Then explain the translator's reason of using the adaptation and variation technique, and describe the effect of both techniques towards the translation quality. This is a prescriptive qualitative study and categorized as an embedded research. The sources of data are 1) script of Batman movie and its translation in Mataraman Javanese, 2) the raters as informant who evaluate the translation in terms of accuracy and acceptability, and 3) the target audiences to rate the comprehension. Based on the research result, the researcher collected 110 data which consist of 48 adaptation data and 62 variation data. The adaptation data in this study are ecology, material culture, social culture, procedure/ activity/ artistic term, economic system and language. Meanwhile, the variation data contain the personal pronouns for first person, second person, and third person translated into speech level of ngoko (showing low politeness), madya (showing middle politeness) and krama (showing high politeness). The use of adaptation and variation techniques by the translator is in line with the purpose of Mataraman Javanese program held by local TV station to accommodate the local wisdom. For that reason, the translation ideology of this subtitle is domestication by employing those translation techniques which are closes to the target language culture. Generally, the use of adaptation and variation techniques in this study is quite accurate, acceptable in the target culture and comprehensible to the target audience.
\end{abstract}

Key words: adaptation technique, variation technique, subtitle

\begin{abstract}
ABSTRAK
Penelitian ini bertujuan untuk mengidentifikasi dan mendeskripsikan unsur budaya yang diterjemahkan dengan teknik adaptasi dan unsur linguistik yang diterjemahkan dengan teknik variasi pada subtitle film Batman versi bahasa Jawa Mataraman. Selanjutnya menjelaskan faktor yang melatarbelakangi penerjemah menggunakan kedua teknik tersebut dan menguraikan implikasinya terhadap kualitas terjemahan. Penelitian ini merupakan penelitian kualitatif preskriptif dengan studi kasus terpancang. Sumber data yaitu 1) naskah dialog dalam film Batman berbahasa Inggris dan subtitle dalam bahasa Jawa Mataraman, 2) para informan atau rater yang menilai keakuratan dan keberterimaan, serta 3) para responden yang menilai pemahaman pemirsa sasaran. Berdasarkan hasil penelitian diperoleh 110 data yang terdiri dari 48 data adaptasi dan 62 data variasi. Data adaptasi dalam penelitian ini adalah ekologi, budaya material, budaya sosial, prosedur/aktivitas/ istilah bidang seni, sistem ekonomi dan bahasa. Untuk data variasi mencakup kata ganti orang pertama, kata ganti orang kedua dan kata ganti orang ketiga yang diterjemahkan dalam bentuk tingkat tutur ngoko, madya dan krama. Adapun faktor yang melatarbelakangi penerjemah menggunakan teknik adaptasi dan variasi
\end{abstract}


adalah tujuan penayangan program bahasa Jawa Mataraman yang diinisiasi oleh stasiun televisi setempat untuk mengakomodasi kearifan lokal. Sehingga ideologi penerjemahan yang dipilih adalah domestikasi yang terealisasi dalam teknik-teknik penerjemahan yang berorientasi pada bahasa sasaran. Secara keseluruhan, penggunaan teknik adaptasi dan variasi pada penelitian ini memiliki akurasi yang cukup tinggi, berterima dalam budaya sasaran dan dapat dipahami pemirsa sasaran dengan baik.

Kata Kunci: teknik penerjemahan adaptasi, teknik penerjemahan variasi, subtitle

\section{PENDAHULUAN}

Pada dekade ini telah banyak program acara dari mancanegara membanjiri stasiun televisi terutama dalam bentuk film atau sinema. Program acara tersebut, mengacu pada UU no 32 tahun 2002 tentang penyiaran, yakni harus diberi teks pada mata siaran asing. Teks dimaksud adalah pengalihan makna atau pesan dari bahasa aslinya atau bahasa sumber ke bahasa sasaran. Dengan demikian pemirsa yang tidak mengerti bahasa asli film tersebut tetap dapat menikmati tontonan yang disajikan dan memahami pesan di dalamnya.

Pengalihan pesan dalam industri hiburan lazim disebut penerjemahan audiovisual. Cintas (2009:4) menyebutkan sejatinya ada lebih dari sepuluh cara yang tercakup dalam ranah penerjemahan audiovisual. Namun dia mengelompokkan kembali menjadi tiga besar bentuk penerjemahan audiovisual yang sering digunakan, yakni subtitle, voiceover dan dubbing. Penerjemahan yang dikaji dalam tulisan ini difokuskan pada subtitle yang merupakan terjemahan tertulis dari dialog asli yang muncul dalam bentuk baris-baris teks yang biasanya terletak di bagian bawah layar (Luyken dalam Georgakopoulou, 2009:21). Dalam proses penerjemahan ini, terjadi peralihan bentuk dari bahasa lisan ke bahasa tulis.

Berbeda dengan terjemahan berupa teks tertulis, subtitle tidak menggantikan bahasa sumber yang ada dalam sebuah film, tetapi bersama-sama dengan bahasa sumber menjadi satu bagian dalam film disertai dengan elemen audio (suara) dan visual (gambar). Dalam pembuatan subtitle, ada beberapa hal teknis yang perlu diperhatikan, yaitu pengaturan waktu kemunculan subtitle pada layar, jumlah karakter atau baris dan ruang penyajian. Seorang penerjemah subtitle atau disebut subtitler harus menyesuaikan teks terjemahan dengan dialog yang dituturkan tokoh dalam film, sehingga ada kepaduan antara tuturan dan terjemahannya yang muncul dalam bentuk teks subtitle pada layar bagian bawah. Kesalahan dalam penyesuaian antara dialog dengan subtitle 
yang muncul dapat mengganggu jalannya keseluruhan cerita. Seorang subtitler juga harus mempertimbangkan kemampuan baca pemirsa. Oleh sebab itu penting sekali mempelajari karakteristik pemirsa sasaran sebelum memulai proses penerjemahan.

Pada penelitian ini, peneliti mengkaji subtitle film Batman yang diterjemahkan ke dalam bahasa Jawa Mataraman. Film Batman dipilih sebagai sumber data penelitian karena film tersebut telah banyak diketahui pemirsa sasaran. Sehingga akan mempermudah pada penilaian kualitas terjemahan yakni aspek keterbacaan atau pemahaman. Film Batman telah diterjemahkan ke dalam beberapa bahasa. Salah satu yang menarik adalah terjemahan ke dalam bahasa Jawa Mataraman. Bahasa Jawa Mataraman adalah ragam bahasa Jawa yang dituturkan oleh masyarakat di sepanjang area Mataraman yang membentang dari Ngawi hingga Kediri. Bahasa Jawa Mataraman, meskipun merupakan ragam bahasa Jawa Timuran, tetapi mendapatkan banyak pengaruh dari bahasa Jawa standar yang dituturkan masyarakat Surakarta dan Yogyakarta atau dikenal dengan daerah Mataram. Sehingga disebut bahasa Jawa Mataraman.

Penerjemahan dari bahasa Inggris ke bahasa Jawa khususnya Mataraman dalam bentuk subtitle film memang belum lama hadir mewarnai dunia penerjemahan audiovisual. Kemunculannya diilhami oleh program basa Jawa Mataraman yang diinisiasi oleh stasiun televisi JTV (Jawa Pos Media Televisi) yang mengkhususkan diri sebagai televisi untuk masyarakat Jawa Timur. Salah satu tujuan penayangan program acara berbahasa Jawa adalah mengakomodasi kearifan lokal. Yaitu untuk mempertahankan eksistensi budaya lokal yang kian tergerus pengaruh budaya asing yang membanjiri dunia pertelevisian tanah air. Fenomena tersebut menginspirasi para penerjemah audiovisual untuk menerjemahkan film mancanegara ke dalam bahasa Jawa Mataraman.

Penelitian ini bertujuan untuk mengidentifikasi dan mendeskripsikan teknik adaptasi untuk menerjemahkan unsur budaya dan teknik variasi yang diterapkan untuk menerjemahkan unsur linguistik pada subtitle film Batman versi bahasa Jawa Mataraman. Kemudian menganalisis implikasinya terhadap kualitas terjemahan yang meliputi aspek keakuratan pengalihan pesan, keberterimaan dalam budaya sasaran dan pemahaman pemirsa sasaran. 


\section{TEORI DAN METODOLOGI}

Secara garis besar, penerjemahan merupakan kegiatan pengalihan pesan dari bahasa sumber (BSu) ke dalam bahasa sasaran (BSa). Catford (1965: 20) mengemukakan pendapat bahwa penerjemahan adalah "the replacement of textual material in one language by equivalent textual material in another language." Penerjemahan merupakan upaya mengganti materi tekstual dalam bahasa sumber dengan materi tekstual yang padan dalam bahasa sasaran. Materi tekstual yang dimaksud oleh Catford mencakup konsep makna. Artinya penerjemahan mensyaratkan kesepadanan makna atau pesan antara BSu dan BSa.

Nida dan Taber mendefinisikan penerjemahan sebagai usaha mencipta kembali pesan dalam bahasa sumber ke dalam bahasa sasaran dengan padanan alami yang sedekat mungkin, pertama dalam hal makna, kemudian gaya bahasa (1982: 12). Baik Catford maupun Nida dan Taber menekankan penerjemahan pada pencarian padanan alami yang sedekat mungkin sehingga menghasilkan pesan yang sama dalam BSa. Lebih detail Nida dan Taber menyertakan gaya bahasa sebagai elemen yang perlu diupayakan sepadan.

Hatim dan Mason (1997) mendefinisikan penerjemahan sebagai tindak komunikasi untuk mengungkapkan kembali suatu pesan dengan melintasi batas-batas budaya dan bahasa antara BSu dan BSa. Tindak komunikasi dimaksudkan adanya upaya penerjemah berkomunikasi dengan pembaca atau pendengar sasaran melalui teks terjemahan yang dihasilkannya. Teks terjemahan disesuaikan dengan karakteristik dan kebutuhan pembaca atau pendengar sasaran yang telah dibidik terlebih dahulu. Dengan demikian penerjemah akan dapat membuahkan karya terjemahan yang mudah dipahami.

Berkaitan dengan kesepadanan dalam penerjemahan, Larson (1984:2) berpendapat bahwa pada dasarnya dalam suatu penerjemahan, perubahan bentuk dalam struktur permukaan (surface structure) tidak dapat dihindarkan karena adanya perbedaan karakteristik antara BSu dan BSa. Sedangkan makna atau pesan merupakan struktur dalam (deep structure) yang menurut para pakar penerjemahan harus dipertahankan. Masih terkait dengan kesepadanan, Machali (2009:141) menegaskan bahwa kesepadanan bukan berarti kesamaan. Kesepadanan lebih dikaitkan pada fungsi teks, dan metode penerjemahan dipilih dalam kaitannya dengan fungsi teks tersebut. Sehingga kesepadanan diukur secara menyeluruh, artinya perubahan apapun yang 
terjadi yang sifatnya lokal, yakni menyangkut kata, frasa dan kalimat harus dilihat dari fungsinya yang lebih tinggi. Sejauh fungsi teks dalam bahasa sasaran tidak bergeser dari fungsi aslinya, maka teks tersebut sepadan dengan aslinya.

Tahap awal sebelum melaksanakan proses penerjemahan dikenal dengan ideologi penerjemahan. Hoed mengutip Venuti (2006: 84) menyampaikan bahwa ideologi yang diterapkan penerjemah merupakan tarik-menarik antara dua kutub yang berlawanan, yaitu antara penerjemahan yang berorientasi pada BSu (foreignizing) dan penerjemahan yang berorientasi pada BSa (domesticating).

Domesticating translation atau domestikasi, kutub yang berpihak pada bahasa sasaran, menghadirkan unsur-unsur bahasa sumber yang diterjemahkan ke dalam bahasa sasaran agar keseluruhan terjemahan hadir sebagai bagian dari bahasa sasaran. Dalam domestikasi penerjemah menentukan segala sesuatu yang diperlukan agar terjemahannya tidak dirasakan sebagai karya asing bagi pembaca atau pemirsanya. Dalam hal ini karya terjemahan kerap dianggap sebagai adaptasi. (dalam Hoed, 2006)

Kajian ini difokuskan pada teknik penerjemahan adaptasi dan variasi. Molina dan Albir (2002) mengemukakan bahwa adaptasi adalah teknik penerjemahan yang digunakan untuk menggantikan unsur budaya BSu dengan unsur budaya BSa yang memiliki karakteristik serupa. Unsur budaya tersebut juga harus akrab dengan pembaca sasaran. Sementara Machali menggunakan istilah prosedur penerjemahan adaptasi (2009) untuk mendefinisikan pengupayaan padanan kultural antara dua situasi tertentu. Beberapa ungkapan kultural yang konsepnya tidak sama antara $\mathrm{BSu}$ dan $\mathrm{BSa}$ memerlukan adaptasi seperti contoh di bawah ini:

BSu : How much do you weigh?

\section{I'm 100 pounds.}

$\mathrm{BSa}$ : Berapa berat badanmu?

Berat badanku $50 \mathrm{~kg}$.

Prosedur pengukuran berat badan di Amerika Serikat menggunakan satuan pound, sedangkan di Indonesia menggunakan kilogram. $1 \mathrm{~kg}=2$ pound. Maka dalam menerjemahkan pengukuran berat badan tersebut perlu dilakukan adaptasi sesuai tradisi yang berlaku pada masyarakat sasaran.

Teknik variasi, menurut Molina dan Albir (2002) adalah teknik penerjemahan dengan mengubah unsur linguistik atau paralinguistik yang memengaruhi varian-varian 
linguistik seperti perubahan nada tekstual, gaya bahasa, dialek sosial, dialek geografis, dan lain-lain. Teknik ini biasa digunakan dalam penerjemahan teks drama. Contoh:

BSu: Alright. I'll phone you later.

BSa : Ya sudah. Aku telepon lagi nanti.

Dalam bahasa sumber, ' $I$ ' dapat digunakan pada situasi formal maupun informal. Dalam bahasa sasaran, terdapat varian-varian untuk menerjemahkannya. Untuk situasi formal lazim digunakan pronomina persona 'saya', sedangkan untuk situasi informal dapat diterjemahkan menjadi 'aku', 'daku', 'gue'.

Penelitian ini merupakan penelitian kualitatif preskriptif yang mengamati fenomena kebahasaan. Disebut penelitian kualitatif karena data yang diperoleh berupa satuan lingual atau gambar yang mempunyai arti lebih dari sekadar angka atau jumlah (Sutopo, 2002). Bogdan dan Taylor mengemukakan bahwa penelitian kualitatif sebagai prosedur penelitian yang menghasilkan data deskriptif berupa kata-kata tertulis atau lisan dari orang-orang dan perilaku yang dapat diamati (dalam Moleong, 2002:3).

Penelitian ini bersifat preskriptif karena merumuskan tindakan pemecahan masalah kawasan yang sudah teridentifikasi, yaitu penggunaan teknik adaptasi dan variasi yang mengerucut pada penilaian kualitas terjemahan. Permasalahanpermasalahan preskriptif berupaya memberikan gambaran atau merumuskan masalah sesuai dengan fakta yang ada. Metode ini meliputi tahap penyusunan rumusan masalah penelitian, kajian pustaka, pengumpulan data, hasil dan pembahasan, simpulan dan rekomendasi terhadap permasalahan terkait.

Penelitian ini menggunakan teknik purposive sampling. Sutopo merumuskan dalam teknik ini peneliti memilih sumber data dan data yang relevan dengan penelitian, serta informan/ responden yang dianggap mengetahui informasi dan segala permasalahan yang diperlukan peneliti secara mendalam dan dapat dipercaya sebagai sumber data (2002: 6). Purposive sampling dalam penelitian ini dibagi dua, sampling untuk data verbal dan untuk data informatif.

\section{TEMUAN DAN PEMBAHASAN}

1.1. Penerapan Teknik Adaptasi pada Subtitle Film Batman

Peneliti menganalisis penerapan teknik adaptasi pada subtitle film Batman versi bahasa Jawa Mataraman yang kemudian dikelompokkan menurut kategori budaya (Newmark, 
1988). Menurut Newmark, terdapat lima kategori budaya yang dapat dijadikan acuan untuk memudahkan penerjemah mencari padanan, yaitu ekologi, budaya material, budaya sosial, prosedur/ tradisi/ aktivitas/ istilah/ konsep, serta bahasa tubuh dan kebiasaan (1988: 95). Pada penelitian yang mengambil data dari subtitle film Batman versi bahasa Jawa Mataraman ini peneliti menemukan dua data yang tidak termasuk kategori budaya versi Newmark, tetapi menurut Koentjaraningrat merupakan unsur kebudayaan (1996: 80), yaitu bahasa dan sistem ekonomi. Berikut contoh data tiap-tiap kategori budaya beserta deskripsinya:

\subsubsection{Ekologi}

- Nama pulau

TSu: - Listen, you didn't come here to ask me to pose nude, because you're going to need a long lens.

- Actually I was in Corto Maltese.

TSa: - Sik sik, awakmu teko mrene ora njaluk aku pose udo kan? Soale awakmu butuh lensa sing dowo.

- Sakjane aku kae ning Papua.

Terdapat persamaan antara definisi Corto Maltese dalam film tersebut dengan versi subtitle-nya (Papua), yakni di kedua pulau tersebut tengah terjadi peperangan. Namun jika dikaji lebih jauh, perang yang terjadi di Corto Maltese jauh berbeda dengan perang di Papua. Di pulau Corto Maltese, perang terjadi antara dua negara adidaya yang memperebutkan supremasi sebagai negara terkuat di dunia baik secara ekonomi, ideologis dan politis yang ditunjang dengan kekuatan militer beserta alutsista tercanggih (https://www.loc.gov/exhibits/archives/sovi.html). Sementara yang terjadi di Papua lebih tepat disebut sebagai konflik horisontal. Yakni keberadaan gerakan separatis OPM yang mengganggu ketertiban dan kenyamanan masyarakat hingga membahayakan kedaulatan negara, sehingga menyebabkan TNI turun tangan untuk menumpas organisasi tersebut.

(http://www.academia.edu/8772952/Usaha_Gerakan_Separatis_Organisasi_Papua_Mer deka_Untuk_Melepaskan_Diri_Dari_NKRI).

\subsubsection{Budaya material}

- Tempat tinggal dan nama jalan

$\mathrm{TSu} \quad$ :- Check something out for me. 
- Yeah.

- Find out what's special about alley at Pearl and Phillips.

TSa :- Aku pengen awakmu ngecek sesuatu.

- Oke.

- Golekono opo sing spesial soal gang ning dalan SoekarnoHatta.

Pada film Batman tersebut, pearl and Phillips digambarkan sebagai sebuah jalan raya yang terhubung dengan beberapa jalan kecil atau gang di beberapa titik. Kemudian dalam teks subtitle diadaptasi menjadi jalan Soekarno-Hatta. Di beberapa kota di Indonesia khususnya wilayah Jawa Timur, nama jalan Soekarno-Hatta dikenal luas, mudah dijumpai dan umumnya berupa jalan raya. Di antaranya di Kediri, Madiun, Magetan, Ponorogo dan Bojonegoro.

- Makanan dan minuman

$\mathrm{TSu}$ : I want a parade. I want hot dogs, balloons, everything. We'll celebrate this $200^{\text {th }}$ anniversary proudly and publicly.

TSa : Aku pingin ono karnaval. Aku pingin sego pecel, balon, baliho, pokoke meriah. Awake dewe bakal ngrayakno ulang tahun kuto ping 200 sing ruame.

Dilihat dari komposisi, kemasan dan penyajian, tentu saja sangat jauh berbeda antara hot dog dan pecel. Hot dog tergolong makanan ringan. Dalam Oxford dictionary (1995:577) hot dog didefinisikan sebagai a long hot sausage served in a soft bread roll, often with onions. Yaitu sosis (daging cincang yang dibumbui dan dikemas dalam selaput berbentuk silinder panjang) yang dimasak dengan cara dipanggang lalu diletakkan di tengah roti berbentuk silinder bersama dengan irisan bawang bombay.

Pada versi subtitle, penerjemah mengadaptasi hot dog dengan pecel. Menurut KBBI luring 1.5, definisi pecel adalah makanan yang terdiri atas sayuran, seperti kacang panjang, bayam, taoge yang disiram dengan kuah sambal kacang. Pecel biasanya disajikan dengan pincuk yang terbuat dari daun pisang. Pecel dapat dijadikan menu makanan berat yang umumnya untuk sarapan. Selain itu dapat pula dijadikan kudapan.

Pada perayaan hari jadi sebuah kota di Amerika Serikat, pengunjung dapat dengan mudah menjumpai stan-stan hot dog. Demikian pula dalam perayaan hari jadi kota-kota di Jawa Timur. Pecel merupakan salah satu menu yang mudah didapatkan. Pertimbangan inilah yang diambil subtitler saat memutuskan mengadaptasi hot dog 
menjadi sego pecel. Ia tidak fokus pada bentuk, komposisi, rasa, dan penyajian, akan tetapi pada momen disajikannya makanan tersebut, yaitu ulang tahun kota.

- Peralatan rumah tangga

TSu: - What are they seeing up there?

- They're all drinking Drano.

TSa : - Opo sing didelok ning duwur kono?

- Cah loro kuwi ngombe Topi Miring.

Drano merupakan cairan pembersih kamar mandi yang umum digunakan oleh masyarakat AS. Dalam konteks cerita di atas, polisi memberikan keterangan palsu kepada bawahannya bahwa dua gelandangan yang ditemukan penuh luka di atap sebuah gedung telah melakukan percobaan bunuh diri dengan meminum Drano. Beberapa kasus bunuh diri yang ditemukan di Amerika Serikat sebagiannya memang meminum drano atau campuran drano dengan cairan kimia. Contoh kasus pada diary ini http://www.thejenniferdiaries.com/2011/07/drano-incident.html.

Pada subtitle, Drano diadaptasi menjadi Topi Miring yang merupakan sebuah merk minuman keras. Sehingga jelas berbeda dengan Drano. Pada beberapa kasus, menenggak Topi Miring dapat menyebabkan kematian apabila diminum dalam jumlah banyak atau dioplos dengan bahan lainnya yang menimbulkan efek merusak organ tubuh, mengganggu penglihatan dan konsentrasi. Seperti pada contoh di portal berita berikut ini http://keprinet.com/2016/03/03/kepri/batam/usai-tenggak-5-botol-topimiring-pengendara-motor-tewas/.

\subsubsection{Budaya sosial}

- Kata sapaan

$\mathrm{TSu}$ : - Who are you?

- Sorry. Bruce Wayne.

TSa :- Sopo sampeyan?

- Sepurane, jenengku Bagus Wiyono.

Nama Bruce lazim digunakan untuk menamai anak laki-laki di Amerika Serikat dan Inggris. Nama tersebut muncul pada Oxford dictionary bagian appendix 5, common first names, male names, halaman 1408 (1995). Sedangkan nama Wayne baru dikenal di AS pada sensus penduduk tahun 1840 (www.anchestry.com). Wayne merupakan nama keluarga imigran dari Inggris dan Wales. Asal mulanya dari abad ke-7 
atau sebelum itu. Wayne adalah derivasi dari Waegn - Waegen - Wain - Wayne. Waegn berasal dari kata Wagon. Nama keluarga Wayne bermakna carter atau driver of a wagon.

Untuk versi subtitle, penerjemah mengadaptasi nama Bruce Wayne menjadi Bagus Wiyono. Nama tersebut sangat identik dengan orang Jawa. Bagus biasanya dipakai untuk nama depan dan nama tengah anak laki-laki. Kemudian Wiyono mencirikan nama khas Jawa dengan akhiran -no. Nama lain berakhiran -no yang kental budaya Jawa misalnya Pujiono, Prayitno, Sumarsono, Sugiyono.

Dalam tradisi masyarakat Jawa, tidak ada aturan baku untuk menggunakan nama keluarga di belakang nama diri. Sehingga nama Wayne yang diadaptasi menjadi Wiyono tidak bertentangan dengan tradisi setempat.

- Hobi dan kesenangan

BSu: - Were you close to him?

- I used to spend summers with him and my grandmother.

BSa: - Awakmu mesti akrab karo eyangmu?

- Iyo. Aku sering preian karo eyang kakung lan eyang putri.

Dalam tradisi AS, musim panas yang berlangsung antara bulan juni sampai agustus merupakan musim liburan. Pada saat musim panas, cuaca bersahabat sehingga sebagian besar warga menghabiskan waktunya berekreasi di luar rumah. Menurut Cambridge dictionary $3^{\text {rd }}$ edition luring, summer adalah the period when most people take their holidays, go to visit places or take part in an activity outside work.

Pada subtitle film Batman versi bahasa Jawa Mataraman, summer diterjemahkan menjadi preian. Dalam hal ini penerjemah memfokuskan pada kegiatan berliburnya, bukan pada bulan-bulan tertentu saat musim panas tiba, atau mencari padanan misal musim kemarau, karena konteksnya penutur (Vicki) bercerita tentang masa remajanya yang bahagia saat berlibur bersama kakek dan neneknya di sebuah rumah di tepi danau. Sehingga penekanannya pada event 'berlibur'.

- Makian

TSu :- Oh, Knox. I got something for you.

- What a dick.

TSa : - Hei, Pras. Aku duwe hadiah kanggo awakmu.

- Jancuk. 
Ungkapan 'what a dick' mengindikasikan umpatan atau makian yang mengandung kata-kata kotor yaitu dick yang bermakna alat kelamin laki-laki (dalam Cambridge dictionary luring 1.5), makian ini mengacu pada bagian tubuh (Jay, 2009). Sementara dalam subtitle diterjemahkan menjadi 'jancuk' yang berarti senggama, mengacu pada aktivitas (Widiasih, 2010). Dalam konteks ini tidak ada kaitan dengan aktivitas persenggamaan, tetapi kata tersebut digunakan untuk mengekspresikan kemarahan dan kekesalan sebagaimana kalimat dalam TSu. Fungsi tuturan tersebut adalah untuk mengekspresikan kemarahan dan kekesalan.

1.1.4. Aktivitas, istilah, prosedur

- Prosedur pengukuran berat badan

$\mathrm{TSu}$ :- How much do you weigh? - About 108, I think.

TSa : - Bobotmu piro? - Koyoke 54, koyoke seh.

Pound merupakan satuan berat yang umum digunakan di Amerika Serikat. 1 pound $=0,5 \mathrm{~kg}$. Sedangkan dalam subtitle versi bahasa Jawa Mataraman, Siti menyebutkan berat badannya dalam satuan $\mathrm{kg}$ yang memang lazim digunakan di Indonesia.

\subsubsection{Sistem ekonomi}

- Mata uang

$\mathrm{TSu}$ : Hey. Give me a dollar. How about it? One dollar.

TSa : Hei, mister. Aku njaluk duite. Piye? Sak repes wae lho.

Repes adalah istilah yang digunakan masyarakat Jawa untuk menyebut mata uang Rupiah, meskipun tidak selalu digunakan dalam aktivitas sehari-hari. Mata uang resmi yang beredar sebagai alat transaksi di Amerika Serikat adalah USD dan di Indonesia secara umum adalah Rupiah.

One dollar, secara literal dapat diterjemahkan sak repes (satu Rupiah). Akan tetapi jika mengacu pada nilai tukar mata uang asing, seharusnya diterjemahkan menjadi 12.000 repes (kurs tahun 2014 saat film tersebut diterjemahkan). Dalam budaya TSu terdapat cetakan uang 1 dollar, sedangkan dalam TSa sudah tidak ditemukan lagi cetakan uang 1 Rupiah. Namun demikian, frasa 'sak repes' masih digunakan dalam 
beberapa kondisi, misalnya untuk menyatakan tak punya uang sama sekali atau bokek. Contoh "Aku gak duwe duit. Mbok sak repes to."

Pada konteks tuturan di atas, one dollar dimaksudkan sebuah angka yang sedikit. Dalam artian si gelandangan meminta sejumlah uang sedikit saja pada turis yang berlalu di hadapannya. Sama halnya dengan frasa sak repes yang menunjukkan jumlah sedikit.

\subsubsection{Bahasa}

$\mathrm{TSu}$ : Are you deaf? You don't speak English?

TSa : Kowe budek opo? Ra iso boso Jowo?

Karena subtitle dihadirkan dalam bahasa Jawa, maka secara otomatis English diadaptasi menjadi boso Jowo (basa Jawa).

\subsection{Penerapan Teknik Variasi pada Subtitle Film Batman}

Untuk mengklasifikasi unsur linguistik yang diterjemahkan dengan teknik variasi, peneliti merujuk pada sistem tingkat tutur (undak usuk bahasa) yang digunakan dalam percakapan sehari-hari oleh masyarakat Jawa Timur khususnya dalam lingkup penutur bahasa Jawa Mataraman. Peneliti berpedoman pada tingkat tutur bahasa Jawa yang disampaikan Poedjosoedarmo (1979).

\subsubsection{Kata Ganti $\mathrm{O} 1$}

TSu: - Anonymous tip. Napier's cleaning out Axis Chemicals. - Why wasn't I told?

TSa: - Ono info teko wong. Jarene Temin ngresiki pabrik kimia. - Kok aku ora diomongi?

Dalam peristiwa tutur tersebut, O1 adalah Commissioner Gordon (Kombes Darto), usia 45 tahun lebih, menjabat kepala polisi, sedang berbicara kepada $\mathrm{O} 2$ yang merupakan anak buahnya. Kata ganti 'aku' digunakan oleh O1 manakala berbicara kepada $\mathrm{O} 2$ yang secara usia lebih muda, status sosial di bawahnya, dan jarak sosial antara O1 dan O2 dekat (Poedjosoedarmo, 1979).

\subsubsection{Kata Ganti $\mathrm{O} 2$}

$\mathrm{TSu}$ : - Lieutenant. Lots of punks in town are scared stiff! They say he drinks blood. They say he can't be killed. 
- I say you're full of shit, Knox.

TSa : - Inspektur, cah-cah berandal ning kene maleh podo wedi. Jarene lowo kuwi ngombe getih. Gek ra iso dipateni.

- Kowe umuk tok, Pras.

O1 adalah seorang perwira polisi, berusia 40-an tahun. Sedangkan O2 adalah wartawan, usia awal 30-an. Selain faktor usia dan status sosial yang berbeda (saat itu berada di lokasi terjadinya kriminalitas sehingga polisi merupakan pihak yang paling berwenang) $\mathrm{O} 1$ bertutur dalam keadaan marah.

$\mathrm{TSu}$ :- What are you doing here?

- I'm here to see some of the wildlife in Gotham City.

TSa : - Terus, lapo awakmu mrene?

- Aku mrene arep golek sing liar-liar ning kuto iki.

Dalam konteks tersebut, $\mathrm{O} 1$ adalah seorang pria berusia 20 -an tahun akhir atau 30-an awal. Berprofesi sebagai wartawan. Sedangkan O2 adalah perempuan berusia sekira 25 tahun. Fotografer yang merangkap wartawan. Pada peristiwa tutur tersebut, keduanya tidak saling mengenal secara pribadi, hanya saling mengetahui lewat karya masing-masing yang dimuat di majalah. O1 menggunakan kata ganti 'awakmu' karena O2 lebih muda dan meskipun belum akrab, tetapi karena menekuni profesi yang sama, dalam peristiwa tutur tersebut keduanya menjadi lebih cepat akrab.

Kata ganti 'awakmu' termasuk tingkat tutur ngoko (Sukesti, 2000; Maryaeni, 2013) tetapi gradasinya di atas 'kowe'. Dengan demikian dapat dikatakan bahwa penggunaan kata ganti 'awakmu' dimaksudkan untuk menghaluskan tuturan (eufemisme) meski bukan untuk menghormati lawan bicara (politeness/ honorifik).

\section{TSu :- The information you requested. \\ - Thank you. \\ TSa : - Info sing njenengan suwun. \\ - Matur nuwun.}

Meskipun secara usia $\mathrm{O} 1$ lebih tua dari O2, bahkan sebaya dengan orangtua O2, tetapi status sosial mereka berbeda. O1 adalah pelayan dan $\mathrm{O} 2$ adalah tuannya. Maka 'you' diterjemahkan menjadi 'njenengan' sebagai bentuk penghormatan. Dalam situasi formal, bentuk krama yang terealisasi dalam kata ganti orang kedua adalah panjenengan. Namun dalam konteks tersebut, O1 dan O2 dikisahkan sangat akrab 
sehingga digunakan kata ganti 'njenengan' yang biasanya dituturkan dalam situasi informal (Sukesti, 2000).

\subsubsection{Kata Ganti O3}

$\mathrm{TSu}$ : - Look, Johnny Gobs got ripped and walked off a roof, all right?

- No, man. That ain't what I heard at all. I hear that the Bat got him.

TSa : - Tak omongi yo, Joni Gembos kuwi mung ciblok teko genteng. Mudheng?

- Gak, Cak. Dudu kuwi sing tak rungokne Jarene de'e dihajar lowo.

Kata 'him' dalam TSu termasuk kelas kata pronomina persona atau kata ganti orang ketiga laki-laki yang mengisi fungsi objek. Him dalam tuturan di atas merujuk pada Johnny (Joni), salah satu teman dari gelandangan yang tewas terjatuh dari atap gedung beberapa malam sebelumnya. Dalam TSa, 'him' diterjemahkan de'e yang merupakan bentuk informal dari pronomina dheke atau deweke. Kata de'e atau dheweke berlaku netral, dalam artian dapat digunakan untuk laki-laki dan perempuan (Poedjosoedarmo, 1979).

\subsection{Kualitas Terjemahan}

Untuk menganalisis kualitas terjemahan, peneliti menggunakan instrumen yang dirumuskan oleh Nababan dkk (2012) yang meliputi aspek keakuratan pengalihan pesan, keberterimaan dalam budaya sasaran dan keterbacaan atau pemahaman pemirsa sasaran. Dalam penilaian ini peneliti melibatkan rater untuk menilai keakuratan dan keberterimaan. Kemudian responden meneliti tingkat keterbacaan. Berikut tabulasi hasil analisis dan kualitas terjemahannya:

\begin{tabular}{|c|c|c|c|c|c|c|c|c|c|c|c|c|c|}
\hline \multirow{3}{*}{ Teknik } & & & & \multirow{3}{*}{$\begin{array}{c}\text { Freku } \\
\text { ensi }\end{array}$} & \multicolumn{9}{|c|}{ Kualitas Terjemahan } \\
\hline & \multirow{2}{*}{\multicolumn{3}{|c|}{ Klasifikasi Data }} & & \multicolumn{3}{|c|}{ Keakuratan } & \multicolumn{3}{|c|}{ Keberterimaan } & \multicolumn{3}{|c|}{ Keterbacaan } \\
\hline & & & & & $\mathbf{A}$ & KA & TA & $\mathbf{B}$ & KB & TB & KT & $\mathbf{K S}$ & KR \\
\hline \multirow{8}{*}{ Adaptasi } & Ekologi & \multicolumn{2}{|l|}{ Pulau } & 1 & - & 1 & - & 1 & - & - & 1 & - & - \\
\hline & \multirow{3}{*}{ Budaya material } & \multicolumn{2}{|c|}{ Makanan dan minuman } & 3 & 2 & 1 & - & 3 & - & - & 3 & - & - \\
\hline & & \multicolumn{2}{|c|}{ Nama jalan dan tempat tinggal } & 4 & 3 & 1 & - & 4 & - & - & 4 & - & - \\
\hline & & \multicolumn{2}{|c|}{ Peralatan rumah tangga } & 1 & - & 1 & - & 1 & - & - & 1 & - & - \\
\hline & \multirow{4}{*}{ Budaya sosial } & \multirow{3}{*}{ Kata Sapaan } & Nama diri & 22 & 19 & 3 & - & 22 & - & - & 22 & - & - \\
\hline & & & Gelar dan jabatan & 1 & 1 & - & - & 1 & - & - & 1 & - & - \\
\hline & & & Sapaan umum & 3 & 3 & - & - & 3 & - & - & 3 & - & - \\
\hline & & \multicolumn{2}{|l|}{ Makian } & 6 & 6 & - & - & 6 & - & - & 5 & 1 & - \\
\hline
\end{tabular}




\begin{tabular}{|c|c|c|c|c|c|c|c|c|c|c|c|c|}
\hline & & Hobi dan kesenangan & 1 & 1 & - & - & 1 & - & - & 1 & - & - \\
\hline & \multirow{3}{*}{$\begin{array}{l}\text { Organisasi, } \\
\text { konsep, aktivitas, } \\
\text { prosedur, istilah }\end{array}$} & prosedur & 2 & 2 & - & - & 2 & - & - & 2 & - & - \\
\hline & & Aktivitas & 1 & 1 & - & - & 1 & - & - & 1 & - & - \\
\hline & & Istilah bidang seni & 1 & 1 & - & - & 1 & - & - & 1 & - & - \\
\hline & Sistem Ekonomi & Mata uang & 1 & 1 & - & - & 1 & - & - & 1 & - & - \\
\hline & \multicolumn{2}{|l|}{ Bahasa } & 1 & 1 & - & - & 1 & - & - & 1 & - & - \\
\hline \multirow{8}{*}{ Variasi } & \multirow{3}{*}{ Kata ganti O1 } & Ngoko (tunggal) & 25 & 25 & - & - & 25 & - & - & 25 & - & - \\
\hline & & Madya (tunggal) & 1 & 1 & - & - & 1 & - & - & 1 & - & - \\
\hline & & Ngoko (jamak) & 5 & 5 & - & - & 5 & - & - & 5 & - & - \\
\hline & \multirow{4}{*}{ Kata ganti $\mathrm{O} 2$} & Ngoko 1 (tunggal) & 9 & 9 & - & - & 9 & - & - & 9 & - & - \\
\hline & & Ngoko 2 (tunggal) & 13 & 13 & - & - & 13 & - & - & 13 & - & - \\
\hline & & Madya (tunggal) & 2 & 2 & - & - & 2 & - & - & 2 & - & - \\
\hline & & Krama (tunggal) & 2 & 2 & - & - & - & 2 & - & 1 & 1 & - \\
\hline & Kata ganti O3 & Ngoko (tunggal) & 5 & 5 & - & - & 4 & 1 & - & 4 & 1 & - \\
\hline \multirow{2}{*}{\multicolumn{3}{|c|}{$\frac{\Sigma}{\%}$}} & 110 & 103 & 7 & 0 & 107 & 3 & 0 & 107 & 3 & 0 \\
\hline & & & 100 & 93,6 & 6,4 & 0 & 97,3 & 2,7 & 0 & 97,3 & 2,7 & 0 \\
\hline
\end{tabular}

\section{SIMPULAN}

Teknik adaptasi yang dikaji dalam penelitian ini terdiri atas adaptasi di bidang ekologi, budaya material, budaya sosial, prosedur/aktivitas/istilah bidang seni, sistem ekonomi dan bahasa. Kemudian teknik variasi yang dianalisis adalah variasi kata ganti dengan menggunakan tingkat tutur bahasa Jawa yang terdiri atas tingkat ngoko, madya dan krama. Dari analisis perolehan data didapat tiga pergeseran makna dari penggunaan teknik adaptasi. Yakni pergeseran subkategori budaya material yang mengubah maksud tuturan $\mathrm{O} 1$ namun tidak berpengaruh terhadap esensi cerita secara keseluruhan. Pergeseran juga ditemukan dalam mengadaptasi budaya sosial berupa kata sapaan dari sapaan formal dalam TSu menjadi sapaan informal dalam TSa. Sedangkan pergeseran lainnya hanya terjadi pada tataran bentuk tanpa menyebabkan distorsi makna.

Kualitas terjemahan dari penggunaan teknik adaptasi pada subtitle film Batman ini dapat dikategorikan baik. Adapun data yang akurat adalah 103 atau 93,6\% dari 110 data, kurang akurat 7 data atau 6,4\%. Data yang berterima mencapai 107 atau 97,3\% dan data kurang berterima berjumlah 3 atau 2,7\%. Data yang mudah dipahami pemirsa terdapat 107 data atau 97,3\% dan kurang dapat dipahami hanya 3 data atau 2,7\%. Dari penilaian informan dan responden yang meliputi aspek keakuratan, keberterimaan dan keterbacaan, seluruhnya tidak ditemukan penilaian paling bawah atau tidak akurat, tidak berterima dan sulit dipahami pemirsa sasaran. 


\section{REFERENSI}

Baker, M. (1992). In other words: a course book on translation. London and New York: Roudledge

Catford, J.C. (1965). A linguistic theory of translation. Oxford: Oxford University Press

Cintas, G.D., \& Anderman, G. (2009). Audiovisual translation: language transfer on screen. Hampshire: Palgrave Macmillan

Hatim, B., \& Mason, I. (1997). The translator as communicator. London \& New York: Routledge

Hoed, B. H. (2006). Penerjemahan dan kebudayaan. Jakarta: PT. Dunia Pustaka Jaya

Holmes, J. S. (1988). The name and nature of translation studies. Dalam Jeremy Munday. (2001). Introducing translation studies: theories and applications (hal. 10-14). London dan New York: Routledge

Hymes, D. (1967). Language in culture and society. New York: Harper and Row

Jay, T. (2009). The utility and ubiquity of Taboo words. Dalam jurnal Perspectives on Psychological Science Vol 4, No 2. Hal 153-161

Koentjaraningrat. (1996). Pengantar antropologi. Jakarta: Rineka Cipta

Larson, M. L. (1984). Meaning-based translation: a guide to cross-language equivalence. Lanham: University Press of America

Machali, R. (2009). Pedoman bagi penerjemah. Bandung: Penerbit Kaifa

Moleong, L.J. (2002). Metodologi penelitian kualitatif. Jakarta: Remaja Rosdakarya

Molina, L., \& Albir, A. (2002). Translation techniques revisited: a dynamic and functionalist approach. Dalam Meta: Journal des Traducteur/Meta: Translation Journal. XL VII, No 4 hal. 498-512

Nababan, M.R. (2008). Teori menerjemah bahasa Inggris. Yogyakarta: Penerbit Kanisius

Nababan, M.R., et al. (2012). Pengembangan model kualitas terjemahan. Dalam jurnal Kajian Linguistik dan Sastra, Vol 24, No. 1, juni 2012, hal. 39-57

Newmark, P. (1988). A textbook of translation. New York: Prentice Hall

Nida, E. A., \& Taber, C. (1974). The teory and practice of translation. Leiden: E.J. Brill 
Nord, C. (1997). Translating as a purposeful activity. Manchester: St. Jerome Publishing.

Nord, C. (2003). Proper names in translations for children: Alice in Wonderland as a case in point. Dalam Meta journal, XLVIII, 1-2, 2003 hal. 182-196

Poedjosoedarmo, S. (1979). Tingkat tutur bahasa Jawa. Jakarta: Pusat Pembinaan dan Pengembangan Bahasa. Departemen Pendidikan dan Kebudayaan.

Sutopo, H. B. (2002). Metodologi Penelitian Kualitatif: Dasar Teori dan Terapannya dalam Penelitian. Surakarta: UNS Press

Widiasih, T. (2010). Pisuhan dalam basa Suroboyoan. Tesis yang tidak dipublikasikan. Surakarta: UNS 